\title{
Prediction of Survival after Myocardial Infarction Using Killip Class
}

\author{
Kourosh Sayehmiri ${ }^{1}$, Diana Sarokhani ${ }^{2}$, Hassan Jahanihashemi ${ }^{3}$, Ali Sayehmiri ${ }^{4}$, \\ Mohamad Taher Sarokhani ${ }^{5}$, Farajollah Hemati ${ }^{6}$, Enayatolah Bakhshi ${ }^{7}$, Morteza Motedayen ${ }^{{ }^{*}}$ \\ ${ }^{1}$ Psychosocial Injuries Research Center, Ilam University of Medical Sciences, Ilam, Iran; ${ }^{2}$ Students Research Committee, Ilam Uni- \\ versity of Medical Sciences, Ilam, Iran; ${ }^{3}$ Biostatistics Department, Qazvin University of Medical Sciences, Qazvin, Iran; ${ }^{4}$ Economic \\ Departments, Ilam University, Ilam, Iran; ${ }^{5}$ Department of Computer Engineering, Science and Research Branch, Islamic Azad Uni- \\ versity, Kermanshah, Iran; ${ }^{6}$ Faculty of Medicine, Ilam University of Medical Sciences, Ilam, Iran; ${ }^{7}$ Department of Statistics and \\ Computer, University of Social Welfare and Rehabilitation Sciences, Tehran, Iran; ${ }^{8}$ Cardio and Vascular Department, Vali e Asr \\ Hospital, Zanjan University of Medical Sciences, Zanjan, Iran. \\ Email: *Sayehmiri@razi.tums.ac.ir
}

Received September $20^{\text {th }}, 2012$; revised October $15^{\text {th }}, 2012$; accepted November $24^{\text {th }}, 2012$

\begin{abstract}
Background: Short and long term predictions of mortality and survival after a myocardial infarction (MI) are important in order to assist physicians in their decision about optimal treatment. We considered the utility of Killip class and other risk factors in the prediction of cardiac death after a MI. Methods: One hundred and eighty two patients with myocardial infarctions were studied over a one year period. Variables include historical factors, physical examination and noninvasive factors measured during hospitalization. All patients were selected in the Imam Khomeini hospital in Ilam City in Iran. Discriminant function and Logistic regression were used to analyze data. The percent of correct classification was compute using the Jack knife method. Results: The one month, 6 months, and one year mortality rate after MI was $25.8,29.7$, and 32.8 percent, respectively. The rate of mortality for women was 1.78 times higher than of the men $(\mathrm{RR}=$ 1.78 , P-value $=0.02$ ). The mean age was 62.45 year. Our results show that the mortality at 1 month and 6 months after MI had a significant relation with Killip class $(\mathrm{P}$-value $<0.01)$. Discriminant function analysis shows that with knowledge of Killip class mortality and patient survival could be predicted with 88.1 percent accuracy up to 6 months. By adding age, cholesterol, and sex it could be increased to 91 percent. The results of logistic regression analysis revealed that there was a significant relation between mortality after MI and variables such a age, sex, cholesterol and the maximum blood urea nitrogen (BUN) level. Conclusion: Death and patient survival of up to one year after MI is predictable using an initial Killip class and other patient characteristics.
\end{abstract}

Keywords: Prediction; Myocardial Infarction; Logistic Regression; Discriminant Function; Killip Class

\section{Introduction}

Heart diseases are the major cause of death in the world wide[1] and it seems that nothing will chnange in this case [2]. It is predicted that one from every three persons will die because of heart diseases [3].

The statistics show that in Iran the mortality because of heart diseases has had an increasing trend so that it has increased from $24.4 \%$ in 1979 to $38 \%$ in 1992 . In Ilam province $33.4 \%$ of deaths was due to heart diseases in 2003 [4].

When patients with symptoms of MI are at first evaluated, clinicians make decisions based on the history, physical examination and ECG. During hospitalization, further decisions are made during acute care based on the

*Corresponding author. clinical course [2]. Prediction of death and survival after MI is very important in planning interventions (including behavioral change, medication, and revascularization) to improve outcome. Knowing relation between baseline clinical characteristics and 30-day, 6-month and 1-year outcome is the main goal of this research that it helps physician to decideand to optimize the treatment of the patient. Determining the value of initial Killip class and other variables in predicting death and survival of patients after MI is the other goal of this research.

\section{Methods}

\subsection{Study Population}

One hundred eighty two patients were followed up one year after MI. Patients were chosen from Imam Khomeini 
hospital (a university hospital) from 2006 to 2009.

\subsection{Follow Up Methods}

An enrollment, detailed personal data were collected; including addresses and telephone number of the patient. Variables including, historical factors, physical examination and noninvasive factors were measured during hospitalization. Only survival or death status was obtained for 30 days, 6 months and one year after MI.

\subsection{Statistical Methods}

Data analyzed with $\chi^{2}$, t-test, logistic regression and Discriminant function. Jack knife method was used for computing the percent of correct classification. Data was analyzed using the SPSS software Ver. 18. A P-value less than 0.05 was considered significant.

\section{Results}

$25.8 \%$ of 182 patients died during 30 days, $29.7 \%$ in 6 months and $32 \%$ one year after MI, respectively. The mean age of the sample was $62.42 \pm 4$, and the percentage of women was $30.9 \%$. Some of the characteristics of the patients with MI were: Smoking 55.6\%, previous MI $24 \%$, previous heart failure $18.7 \%$, previous hypertension 46.3\%. Tables 1-3 showed the baseline clinical and demographic characteristic in the patients died during 30-day, six-month and one-year after MI.

There was a significant relationship between sex and 30-day mortality after MI $\left(\mathrm{RR}=1.78, \chi^{2}=5.38, \mathrm{P}=\right.$ $0.02)$. The rate for female to die 6 months after MI was higher than for male (45.1 vs. $26.1, \mathrm{RR}=1.7, \mathrm{P}=0.019)$. There was the relation: $\mathrm{Y}=\operatorname{Ln}(\mathrm{p} / 1-\mathrm{p})=-2.98+$ $0.038 *$ Age. Between age and survival and death 30 days after MI that it shows with increasing every 10 years to age the odds of death increase 1.47 times. The percent of correct classification in predicting death and survival with using age was $74.3 \%$. Logistic regression between age and mortality after 6 months from MI was: $\operatorname{Ln}(\mathrm{p} / 1-\mathrm{p})=-3.8$ +0.049 age; $(\mathrm{P}=0.000)$ that shows with increasing age the prognosis of patient will be worse. There was logistic

Table 1. Comparison baseline clinical and demographic characteristic in the patients died during 30 days after MI.

\begin{tabular}{|c|c|c|c|c|c|c|c|}
\hline Variable & Status & Frequency & Mean & Standard deviation & Standard error & $\mathrm{T}$ & $\mathrm{P}$ \\
\hline \multirow{2}{*}{ Age } & Death & 47 & 67.14 & 17.86 & 2.6 & 2.58 & 0.0011 \\
\hline & Survival & 126 & 60.7 & 13.6 & 1.17 & & \\
\hline \multirow{2}{*}{ Heart rate } & Death & 15 & 83.2 & 7.8 & 3.6 & 0.7 & 0.49 \\
\hline & Survival & 46 & 80.5 & 43.2 & 1.6 & & \\
\hline \multirow{2}{*}{ SBP } & Death & 17 & 80.6 & 43.2 & 10.5 & 0.4 & 0.68 \\
\hline & Survival & 47 & 118.3 & 28.2 & 4.1 & & \\
\hline \multirow{2}{*}{ DBP } & Death & 16 & 113.6 & 19.5 & 4.1 & 0.24 & 0.8 \\
\hline & Survival & 49 & 69 & 15.1 & 4.8 & & \\
\hline \multirow{2}{*}{ Cholesterol } & Death & 23 & 170.1 & 53.5 & 11.2 & 2.88 & 0.007 \\
\hline & Survival & 127 & 47.2 & 47.2 & 4.2 & & \\
\hline \multirow{2}{*}{ CPK } & Death & 19 & 548 & 447 & 109 & 1.65 & 0.11 \\
\hline & Survival & 7 & 903.6 & 509.8 & 192.7 & & \\
\hline \multirow{2}{*}{ Max BUN } & Death & 23 & 53.1 & 30.2 & 6.3 & 2.57 & 0.01 \\
\hline & Survival & 52 & 33 & 12.7 & 1.8 & & \\
\hline \multirow{2}{*}{ Max QRS } & Death & 9 & 2.1 & 1.2 & 0.42 & 0.5 & 0.67 \\
\hline & Survival & 27 & 2.5 & 2.4 & 0.47 & & \\
\hline \multirow{2}{*}{ PR } & Death & 9 & 4.7 & 3.2 & 1.1 & 0.42 & 0.67 \\
\hline & Survival & 27 & 5.3 & 3.4 & 0.65 & & \\
\hline \multirow{2}{*}{ QT } & Death & 8 & 8.5 & 3.4 & 1.2 & 0.15 & 0.87 \\
\hline & Survival & 25 & 8.9 & 6.7 & 1.3 & & \\
\hline
\end{tabular}


Table 2. Comparision baseline clinical and demographic characteristic in the patients died during months after MI.

\begin{tabular}{|c|c|c|c|c|c|c|c|}
\hline Variable & Status & Frequency & Mean & Standard deviation & Standard error & $\mathrm{T}$ & $\mathrm{P}$ \\
\hline \multirow{2}{*}{ Age } & Death & 54 & 69 & 6.9 & 2.3 & 39.7 & 0.000 \\
\hline & Survival & 109 & 59.6 & 12.8 & 1.2 & & \\
\hline \multirow{2}{*}{ Heart rate } & Death & 17 & 83.3 & 13.6 & 3.3 & 1.15 & 0.25 \\
\hline & Survival & 36 & 79.8 & 8.3 & 1.3 & & \\
\hline \multirow{2}{*}{ SBP } & Death & 20 & 113.7 & 40.8 & 9.12 & .24 & 0.8 \\
\hline & Survival & 37 & 116.1 & 30.3 & 4.4 & & \\
\hline \multirow{2}{*}{ DBP } & Death & 19 & 65 & 19.8 & 4.4 & 1.57 & 0.12 \\
\hline & Survival & 39 & 72.3 & 14.9 & 2.4 & & \\
\hline Cholesterol & Death & 40 & 190.7 & 59.2 & 9.3 & 0.71 & 0.47 \\
\hline \multirow{2}{*}{ CPK } & Death & 37 & 1773 & 1466 & 241.3 & 1.14 & 0.26 \\
\hline & Survival & 92 & 1499 & 1173 & 122.4 & & \\
\hline \multirow{2}{*}{ Max BUN } & Death & 21 & 52.7 & 31.4 & 6.8 & 2.5 & \\
\hline & Survival & 42 & 38.7 & 12.5 & 1.9 & & \\
\hline \multirow{2}{*}{ Max QRS } & Death & 12 & 2.3 & 1.4 & 0.4 & 0.17 & 0.86 \\
\hline & Survival & 42 & 2.4 & 2.5 & 0.06 & & \\
\hline \multirow{2}{*}{ PR } & Death & 12 & 5.7 & 3.4 & 0.9 & 0.71 & 0.47 \\
\hline & Survival & 42 & 4.8 & 3.3 & 0.7 & & \\
\hline \multirow{2}{*}{ QT } & Death & 9 & 8.80 & 3.32 & 1.1 & 0.015 & 0.98 \\
\hline & Survival & 24 & 8.83 & 6.8 & 1.4 & 24 & \\
\hline
\end{tabular}

Table 3. Comparision baseline clinical and demographic characteristic in the patients died during one year after MI.

\begin{tabular}{|c|c|c|c|c|c|c|c|}
\hline Variable & Status & Frequency & Mean & Standard deviation & Standard error & $\mathrm{T}$ & $\mathrm{P}$ \\
\hline \multirow{2}{*}{ Age } & Death & 32 & 66.5 & 17.4 & 3.1 & 3.58 & 0.000 \\
\hline & Survival & 10 & 55.5 & 14 & 4.4 & & \\
\hline \multirow{2}{*}{ Heart rate } & Death & 18 & 77.7 & 13.2 & 2.5 & 1.31 & 0.19 \\
\hline & Survival & 9 & 110.2 & 7.72 & 8.7 & & \\
\hline \multirow{2}{*}{ SBP } & Death & 22 & 110.3 & 41.2 & 8.7 & 0.34 & 0.74 \\
\hline & Survival & 8 & 115.6 & 37.5 & 13.3 & & \\
\hline \multirow{2}{*}{ DBP } & Death & 20 & 64.75 & 19.3 & 4.3 & 1.4 & 0.17 \\
\hline & Survival & 10 & 72 & 9.2 & 2.9 & & \\
\hline Cholesterol lipid & Death & 23 & 170.1 & 53.5 & 11.2 & 2.88 & 0.007 \\
\hline \multirow{2}{*}{$\mathrm{CPK}$} & Death & 19 & 548 & 447 & 109 & 1.65 & 0.11 \\
\hline & Survival & 7 & 903.6 & 509.8 & 192.7 & & \\
\hline \multirow{2}{*}{ Max BUN } & Death & 23 & 53.1 & 30.2 & 6.3 & 2.57 & 0.01 \\
\hline & Survival & 10 & 33.5 & 10.7 & 3.38 & & \\
\hline \multirow{2}{*}{ Max QRS } & Death & 12 & 2.3 & .36 & 2.1 & 1.25 & 0.23 \\
\hline & Survival & 3 & 3.8 & 3.8 & 0.36 & & \\
\hline \multirow{2}{*}{ PR } & Death & 3 & 3.8 & 0.36 & 2.08 & 1.14 & 0.3 \\
\hline & Survival & 3 & 4 & 2 & 1.1 & & \\
\hline \multirow{2}{*}{ QT } & Death & 9 & 8.8 & 3.2 & 1.1 & 0.13 & 0.9 \\
\hline & Survival & 3 & 9 & 1.7 & 1 & & \\
\hline
\end{tabular}


regression equation; $\operatorname{Ln}(\mathrm{p} / 1-\mathrm{p})=-2.033+0.0334 \mathrm{Max}$ (BUN) between mortality 30 days after MI and max BUN that it was significance.

Figures 1 and 2 show, with increasing Killip class after MI, the hazard of death, 30-day and 6-month after MI was increased $(\mathrm{P}<0.01)$. The rate of death in clinical class 3, 4 is significantly higher that clinical classes 1,2 $(\mathrm{P}<0.01)$. The multivariate logistic model

$$
Y=\frac{\exp \left(\alpha+\beta_{1} x_{1}+\beta_{2} x_{2}+\beta_{3} x_{3}+\beta_{4} x_{4}\right)}{1+\exp \left(\alpha+\beta_{1} x_{1}+\beta_{2} x_{2}+\beta_{3} x_{3}+\beta_{4} x_{4}\right)}
$$

with independed variables; $x_{1}$ : age, $x_{2}: \max (\mathrm{BUN}), x_{3}$ : cholesterol lipid, $x_{4}$ : Killip class was considered.

With using forward stepwise method the final model was estimated as: $\operatorname{Ln}(\mathrm{p} / 1-\mathrm{p})=-5.71+1.98 x_{4}$ that shows Killip classification has had strong relationship with death and survival 30-day after MI. The percent of correct classification in the survived group and death group was 91.1 and 88.1 respectively that shows this model has high accuracy in predicting death and survival 30 days after MI. The total correct classification was $88.1 \%$. For 6 months after MI the total correct classification with Killip class was $90 \%(95.9 \%$ in the survival group and $75 \%$ in the death group). In the prediction death and survival the power of logistic regression and discriminant function was approximately same.

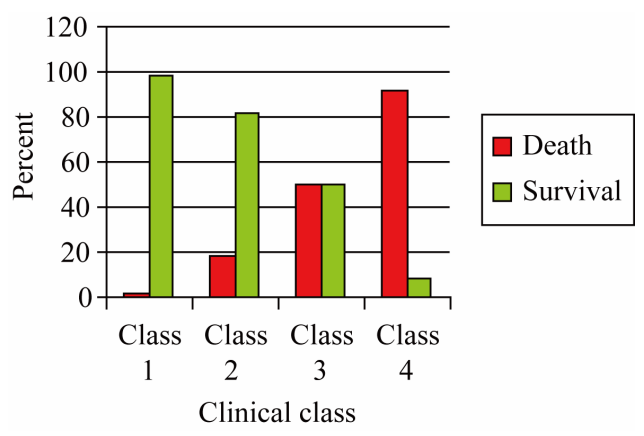

Figure 1. Frequency of death and survival after 30 days of MI according to clinical class.

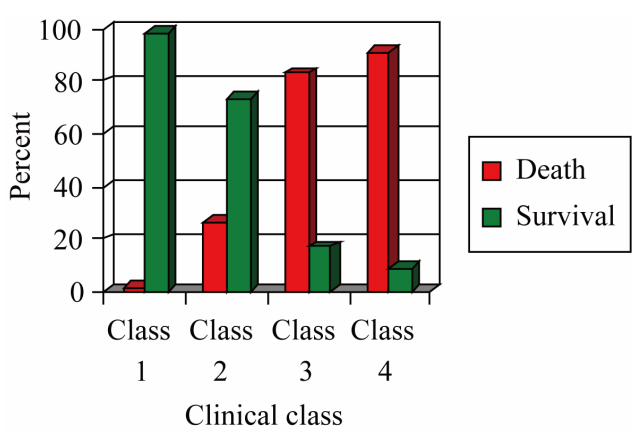

Figure 2. Frequency of death and survival after six months of MI according to clinical class.

\section{Discussion}

The objective of this research was to find predictive factors of death and survival after MI using statistical models. In the survey of 182 patients, $25.8 \%, 29.7 \%$ and $32 \%$ died during 30 days, 6 months and one year after MI, respectively. In Korhonen, P., study during a mean follow-up of 50 months, 30 patients (19\%) died [5].

The mean age patients that suffered MI was 62.45 years (67.14 years the group that died 30 day after MI and 60.7 years in the survived groups. It shows that the older patient have a worse prognosis after MI $(\mathrm{P}<0.05)$. In a research that was done by E.modson et al. on 818 patients the mean of age with MI was $64 \pm 15$ [6]. In a research did by Brender et al. the median of age patient with MI was 62 [7]. The logistic regression shows that there is a relation between age and mortality, so that with increasing of every 10 years to patients age, the probability of death 6 months after MI, increases 1.63 times. Discriminant function analysis shows with having the age of patients with accuracy $74 \%$ it can be predicted death and survival of patients 6 months after MI. Many research show that age is an independed predictive factor for prediction death after MI $[2,8,9]$. Killip class was the most important variable in predicting death and survival after MI $[2-4,7,10,11]$. In a research was done by Hurtmut $\mathrm{H}$. et al. by using Discriminant function with 16 variables the death and mortality of patients 30 days after MI $86 \%$ deaths and $96 \%$ survivals were predicted [12]. Sahasakul et al. show that age, a previous infarct, high Killip class, cardiomegaly, high serum concentrations of cardiac enzymes, a low ejection fraction, and a high wall motion score index correlated significantly with in-hospital mortality. Age and wall motion score index predicted inhospital mortality with a sensitivity of $76.5 \%$, a specificity of $91.5 \%$, and a predictive accuracy of $89.2 \%$ [13]. Hsu, L. et al. derived an index for predicting coronary events in the first year after a myocardial infarction using: 1) previous infarction/angina; 2) radiological evidence of cardiomegaly or lung congestion in the Coronary Care Unit; 3) non-Q wave infarction and (4, 5 and 6) angina, atrial arrhythmias and a decrease in $\mathrm{R}$ wave amplitude in V5 during a pre-discharge exercise test. The jack-knife method in discriminant function classified correctly $71.2 \%$ of those with events and $72.6 \%$ of those without events. In patients with discriminant scores greater than + $0.2,82 \%$ developed events [14].

In a research was done on 40,121 patients by Collif. R. M. et al. [10] Cox proportional hazard model shows Killip class, age, QRS, SBP, HR and smoking are important variables in predicting death and survival after MI.

Prediction death and survival after MI was done in many researches with different variables [5,9,15-18] some prediction models were optimal for short time pre- 
diction $[11,13,19]$ and some for long time prediction $[14$, 20-22].

To sum up death and survival of patients up to one year after MI is predictable using age, cholesterol, sex, $\max$ BUN, and Killip class.

\section{REFERENCES}

[1] C. J. L. Murray and A. D. Lopez, “Alternative Projection of Mortality and Disability by Cause 1990-2020: Global Burden of Disease Study," Lancet, Vol. 349, 1997, pp. 1498-1504.

[2] R. M. Califf, K. S. Pieper, K. L. Lee, F. Van De Werf, R. J. Simes, P. W. Armstrong and E. J. Topol, "Prediction of 1-Year Survival after Thrombolysis for Acute Myocardial Infarction in the Global Utilization of Streptokinase and TPA for Occluded Coronary Arteries Trial," Circulation, Vol. 101, No. 19, 2000, pp. 2231-2238. doi:10.1161/01.CIR.101.19.2231

[3] D. P. Zipes, "Braunwald's: Heart Diseases: A Text Book of Cardiovascular Medicine," Vol. 7, W.B. Saunders, Philadelphia, 2005.

[4] K. Sayehmiri, "Prediction Death and Survival 5 Days after Myocardial Infarction by Using Multivariate Statistics," Tehran, 1997.

[5] P. Korhonen, T. Husa, T. Konttila, I. Tierala, M. Makijarvi, H. Vaananen and L. Toivonen, "Complex T-Wave Morphology in Body Surface Potential Mapping in Prediction of Arrhythmic Events in Patients with Acute Myocardial Infarction and Cardiac Dysfunction," Europace, Vol. 11, No. 4, 2009, pp. 514-520.

doi:10.1093/europace/eup051

[6] E. B. Madsen, et al., "Prediction of Late Mortality after Myocardial Infarction from Variables Measured at Different Time during Hospitalization," American Journal of Cardiology, Vol. 53, No. 1, 1984, pp. 47-54.

[7] S. J. Brener and S. G. Ellis, "Predictors of Death and Survival at 30 Days after Primary Angioplasty," American Heart Journal, Vol. 139, No. 3, 2000, p. 5.

[8] T. H. Makikallio, P. Barthel, R. Schneider, A. Bauer, J. M. Tapanainen, M. P. Tulppo, G. Schmidt and H. V. Huikuri, "Prediction of Sudden Cardiac Death after Acute Myocardial Infarction: Role of Holter Monitoring in the Modern Treatment Era," European Heart Journal, Vol. 26, No. 8, 2005, pp. 762-769. doi:10.1093/eurheartj/ehi188

[9] H. K. Park, S. J. Yoon, H. S. Ahn, L. S. Ahn, H. J. Seo, S. I. Lee and K. S. Lee, "Comparison of Risk-Adjustment Models Using Administrative or Clinical Data for Outcome Prediction in Patients after Myocardial Infarction or Coronary Bypass Surgery in Korea," International Journal of Clinical Practice, Vol. 61, No. 7, 2007, pp. 10861090. doi:10.1111/j.1742-1241.2007.01345.x

[10] R. M. Califf, et al., "Prediction of 1-Year Survival after Thrombolysis for Acute Myocardial Infarction in the Global Utilization of Streptokinase and TPA for Occluded coronary Arteries Trial," Circulation, Vol. 101, 2000, pp. 2231-2238.
[11] P. D. Verdoum, et al., "Short Term Survival after Acute Myocardial Infarction Predicted by Homodynamic Parameters," Circulation, Vol. 52, 1975, pp. 413-419.

[12] H. Henning, et al., "Prognosis after Acute Myocardial Infarction a Multivariate Analysis of Mortality and Survival," Circulation, Vol. 59, No. 6, 1997, pp. 1124-1136.

[13] Y. Sahasakul, S. Chaithiraphan, P. Panchavinnin, P. Jootar, V. Thongtang, N. Srivanasont, N. Charoenchob and C. Kangkagate, "Multivariate Analysis in the Prediction of Death in Hospital after Acute Myocardial Infarction," British Heart Journal, Vol. 64, No. 3, 1990, pp. 182-185. doi:10.1136/hrt.64.3.182

[14] L. Hsu, M. P. Senaratne, S. De-Silva, R. E. Rossall and T. Kappagoda, "Prediction of Coronary Events Following Myocardial Infarction Using a Discriminant Function Analysis," Journal of Chronic Diseases, Vol. 39, No. 7, 1986, pp. 543-552. doi:10.1016/0021-9681(86)90199-2

[15] G. Dwivedi, R. Janardhanan, S. A. Hayat, T. K. Lim and R. Senior, "Improved Prediction of Outcome by Contrast Echocardiography Determined Left Ventricular Remodeling Parameters Compared to Unenhanced Echocardiography in Patients Following Acute Myocardial Infarction," European Journal of Echocardiography, Vol. 10, No. 8, 2009, pp. 933-940. doi:10.1093/ejechocard/jep099

[16] S. Bangalore, S. S. Yao and F. A. Chaudhry, "Prediction of Myocardial Infarction versus Cardiac Death by Stress Echocardiography," Journal of the American Society of Echocardiography, Vol. 22, No. 3, 2009, pp. 261-267. doi:10.1016/j.echo.2008.12.022

[17] N. Rahman, K. A. Kazmi and M. Yousaf, "Non-Invasive Prediction of ST Elevation Myocardial Infarction Complications by Left Ventricular Tei Index," Journal of the Pakistan Medical Association, Vol. 59, No. 2, 2009, pp. 75-78.

[18] K. A. Fox, O. H. Dabbous, R. J. Goldberg, K. S. Pieper, K. A. Eagle, F. Van de Werf, A. Avezum, S. G. Goodman, M. D. Flather, F. A. Anderson Jr., et al., "Prediction of Risk of Death and Myocardial Infarction in the Six Months after Presentation with Acute Coronary Syndrome: Prospective Multinational Observational Study (GRACE)," British Medical Journal, Vol. 333, No. 7578, 2006, pp. 1091. doi:10.1136/bmj.38985.646481.55

[19] T. Lundman, "Short and Long-Term Prognosis of Patients with Acute Myocardial Infarction (AMI) and Prediction of Sudden Death," Forensic Science, Vol. 8, No. 1, 1976, pp. 77-87. doi:10.1016/0300-9432(76)90050-9

[20] M. J. Young, L. F. McMahon Jr. and J. K. Stross, "Prediction Rules for Patients with Suspected Myocardial Infarction. Applying Guidelines in Community Hospitals," Archives of International Medicine, Vol. 147, No. 7, 1987, pp. 1219-1222. doi:10.1001/archinte.147.7.1219

[21] G. M. De Ferrari and P. J. Schwartz, "Sudden Death after Myocardial Infarction. Prediction Based on the Baroreceptor Reflex," Arch Mal Coeur Vaiss, Vol. 83, No. 10, 1990, pp. 1521-1527.

[22] K. Piestrzeniewicz, K. Luczak and J. H. Goch, "Value of Blood Adipose Tissue Hormones Concentration-Adiponectin, Resistin and Leptin in the Prediction of Major 
Adverse Cardiac Events (MACE) in 1-Year Follow-Up after Primary Percutaneous Coronary Intervention in ST-Segment Elevation Acute Myocardial Infarction,"
Neuroendocrinol Letters, Vol. 29, No. 4, 2008, pp. 581588. 